\title{
Pursuing gender equality in Astronomy in basic education: the case of the project "Girls in the Museum of Astronomy and Related Sciences"
}

\author{
Sandra Benitez-Herrera ${ }^{1,2,1,}$ Patrícia F. Spinelli ${ }^{1}$, Sonia $\mathrm{Mano}^{2}$ and Ana Paula \\ Germano $^{1,3}$ \\ ${ }^{1}$ Museu de Astronomia e Ciências Afins, Coordenação de Educação em Ciências, Rua General \\ Bruce 586, Rio de Janeiro, Brazil \\ ${ }^{2}$ Museu da Vida, Fundação Oswaldo Cruz (Fiocruz), Av. Brasil, 4365 - Manguinhos, Rio de \\ Janeiro, Brazil \\ ${ }^{3}$ Universidade Federal Fluminense, Rua Tiradentes, 148, Niterói, Brazil
}

\begin{abstract}
It is well known that the number of women in scientific careers is significantly lower than the number of men, especially in Science, Technology, Engineering and Mathematics (STEM) areas. Considering that science should be used for the benefit of all, by excluding women from the production process of scientific knowledge, we are giving up of $50 \%$ of the intellectual capacity to different science fields. Thus, the Museum of Astronomy and Related Sciences, whose mission is to expand society's access to scientific knowledge, promotes the project "Girls in the Museum", aimed at the continuous education of seven high-school female students in topics of astronomy with the goal of stimulating them into liking science. Concurrently with the project, interviews were conducted to evaluate the initiative according to the participants' perspectives, as well as to understand their perceptions about science prior and after six months of the project. We found that the participants were satisfied with the format and content of the project, comprised of theoretical talks and practical workshops. The resulting discourses show that they now view science as something closer to their lives and are more confident to promote scientific discussions. These results show the importance of providing young females with role models they can look up, especially at the age when they are about to make decisions concerning their future career.
\end{abstract}

\section{Introduction}

Science is a social institution that is neither univocal nor neutral, but historically and geographically situated. Therefore it is possible that it reproduces similar social struggles of the society in which it is produced and can be sometimes used as a justification for domination [1]. An example is the recurring gender bias present in science, which causes two well-differentiated effects: 1) Horizontal exclusion or gender tracking and 2) Vertical exclusion or glass ceiling [2]. In this paper we discuss the first effect in the light of a gender-inclusion science outreach project, "Girls in the Museum", currently taking place at the Museum of Astronomy and Related Sciences (MAST), in Rio de Janeiro, Brazil.

1 Corresponding author: sandra.benitez.herrera@gmail.com 
The disparity between the number of men and women scientists in Academia depends on several factors, according to the Why So Few Women report [3]. These factors can be divided into categories, which are related to social and psychological factors, but especially due to the influence of stereotypes reinforcing the idea that women have no talent for scientific work. Social prejudices about the lack of cognitive abilities are one of the most common arguments to justify women's withdrawal from STEM careers.

Specifically, horizontal exclusion in science originates from the difference in expectations and attitudes towards boys and girls by families, teachers and society in general. From the earliest years, girls are directed towards areas related with nursing or teaching, and are little encouraged to like science disciplines [4]. The scarcity of leading roles models to be emulated by girls in science and engineering also stands out as one of the fundamental reasons for perpetuating this segregation [5].

In fact, recent research shows that the prejudices about women's intellectual abilities appear early in childhood. The Science journal published an article early this year showing that girls learn to underestimate their gender from the age of six, when they begin to associate high-level intellectual ability (brilliance, genius...) with men more than women [6]. Also at age 6, girls begin to avoid activities said to be for children who are "really, really smart." These ideas accompany girls throughout Elementary and Middle School and, in the crucial moment of making a decision about their career, they choose courses related to humanities, caring or teaching. Gender tracking also causes a systematic devaluation of these "feminine" professions in the labour market [2].

In Brazil, it is estimated that the number of female doctors in so-called hard sciences is $31 \%$, according to data by the National Research Council (CNPq, 2015). However, in some fields such as Astronomy, there was almost no increment in the number of female researchers in the last two decades, as pointed out in the study by [7]. This research provided the absolute numbers of women belonging to the International Astronomical Union from countries with more than 40 members, as is the case of Brazil, and showed that only $22.7 \%$ of astronomers were women in Brazil in 2009. This percentage is currently $28 \%$, considering more recent statistics from the Brazilian Astronomical Society.

\section{The project "Girls in the Museum"}

The project "Girls in the Museum" is a science education program that seeks to motivate female high school students into liking science and prepare them as mediators ${ }^{2}$ of science museums. The project uses Astronomy as an inspiring tool and a gateway to other scientific disciplines like physics, chemistry or mathematics, to inspire the students and involve them in scientific practices. In this way, the project intends to promote gender inclusion through science education in non-formal spaces, breaking down social barriers and prejudices that prevent girls and young women from pursuing scientific careers. Ultimately, it aims at presenting different possibilities available to the students, who will soon have to decide about their future.

To achieve these goals, three distinct phases were defined for the Project. The first six-month period, from July to December 2016, consisted of a training in different subjects of astronomy and science education. This phase was completed last year and constitutes the basis of the research presented in this paper (see next section). From February to September 2017, participants were working on the design and development of experiments and education activities based on the scientific and pedagogical knowledge acquired during the first phase. In this second phase, they acted as mediators

\footnotetext{
2 Mediators are the people who are responsible for welcoming the public and carrying out the activity at the museum. They allow the visitors to learn more about the themes presented and make their experience significant. There are many names for this type of person in the literature: educator, monitor, presenter, and guide, among others. However, throughout this paper, we will always use the word "mediator" to refer to this person.
} 
in the regular educational activities and events offered to the general public at MAST. The third phase of the project took place in October 2017, when the students exhibited their experiments and activities developed throughout the year during the Science and Technology National Week.

\subsection{The preparation phase}

The first phase of the project "Girls in the Museum" consisted of a series of theoretical lectures and practical workshops that addressed topics in Astronomy in a dynamic and inspiring way, in order to stimulate the interest of the students. Other subjects related to science education were also included, such as, mediation in museums, pedagogical principles or the situation of women in science. The sessions took place twice a month on Fridays, between 2 to $5 \mathrm{pm}$. The students were encouraged to ask questions and interact with the invited lecturers and workshop leaders at any time.

In addition, one weekend per month, the students came to MAST to observe the educational activities offered for the public and to familiarize themselves with the practice of mediation. The total time of the preparation phase, taking into account weekends, was about 50 hours. In the following sections, we describe in more detail the activities organized for this phase.

\subsubsection{Astronomy related activities}

Several lectures were given by scientists from well-known Brazilian institutions with long tradition in Astronomy research, such as the National Observatory (ON), Federal University of Rio Grande do Sul (UFRGS), Federal University of Rio de Janeiro (UFRJ), and MAST itself. The topics of the lectures were:

- A universe of galaxies, where the students learned about the different types of galaxies, their structure and ways to observe them. They also discovered about the black hole that "lives" at the centre of our own Galaxy.

- Star clusters, where the participants discussed these interesting astronomical objects, used to estimate the age of the universe.

- Meteors, asteroids and comets, where the students understood the difference between these objects and learned about the formation and evolution of our solar system.

- The Sun, where students were introduced to the physics of our star and the observable characteristics of its surface, such as sunspots and flares.

- Cosmology, where the students were presented with a broad overview of the existing cosmological data, e.g. gravitational lensing or supernovae, and the standard cosmological model of dark matter and dark energy.

In addition to the theoretical lectures, workshops and visits to astronomy-related exhibitions were organized during this time. A practical hands-on activity about the Sun was performed a few sessions after the thematic lecture to better understand our star. For this, we used the "Solar Rotation" activity from the GalileoMobile handbook of activities $^{3}$, consisting on a series of images taken by the SOHO satellite in which the students could identified groups of Sun's spots "moving" along the Sun's surface over a month. This way, they visualized the structure of the Sun's spots and used them to calculate the period of the Sun.

A visit to the Heliometer from the National Observatory that shares the campus with MAST followed, so the students could understand the principles behind projection methods for solar observation and see how measurements of variations of the star's diameter are done. A visit to the Visions of Light exhibition was planned, too ${ }^{4}$. Here students learned about the expansion of the Universe, the Cosmic Microwave Background and the Sobral solar eclipse that helped to confirm Einstein's general

3 http://www.galileo-mobile.org/galileomobile-resources/galileomobile-handbooks

4 http://site.mast.br/hotsite_luz/index.html 
relativity in 1919. At the Solar System external exhibition, the students travelled from one planet to another and recognized their relative sizes and distances from the Sun, perceiving how huge these are and how much "empty space" lies between planets and stars.

A great asset of the course was the contact the students had with female scientists that participated in the lectures and workshops. At one of the sessions, an informal chat between the participants and Prof. Ana Chies Santos, Brazilian L'Oréal-UNESCO Prize for Women in Science laureate, was organized. In a relaxed atmosphere and for more than an hour, students asked multiple questions about her research field, her daily work as an astronomer and were curious about her personal life and her thoughts on family conciliation. These encounters made a significant difference in the perception girls had of the scientist's figure after the preparation period (see section 5).

As mentioned before, during the first period, the students also came one weekend per month to the Museum to observe how the educational activities were carried out by the team of MAST educators. The hands-on activities are usually designed to benefit different types of public (children, young, adults...) and encourage the construction or manipulation of a scientific instrument or experiment. These were:

- Cooking with science, where the public learns about the chemical, physical and biological processes that occur in the kitchen while cooking tasty recipes. During the activity, visitors get their hands on and, in a playful way, understand the scientific concepts present in everyday life.

- AstroMania, where the visitors understand how to build and use astronomical instruments, such as sundials, astrolabes, planispheres, spectrographs, among others.

- $\quad$ Playing with Math, where the public forgets their fear about Mathematics by playing fun games and riddles.

- Sun observation with telescopes, a moment for the public to become astronomers and observe the Sun's spots and flares using Personal Solar Telescopes (PST).

\subsubsection{Mediation in Science Museums}

An element of vital importance in science museums is the figure of the mediator, who acts as a bridge between the visiting public and the different spaces of the museum. Research shows that the visit to a museum becomes richer and socially more stimulating when supported by human mediation [8].

The "Girls at the Museum" project intends to offer professional qualification in the area of mediation in science museums, besides promoting the interest of students in science. This specific training contributes to the future of the students since they get in contact with several types of knowledge, such as: 1) Science and history of science; 2) Construction of scientific knowledge; 3) The functioning of museums: history of the institution, use of the equipments and conception of the exhibitions [9].

In some of the bi-weekly sessions, several issues related to education in museums, constructivist pedagogy and the practice of mediation in exhibitions and outreach activities were addressed. The lecture "Pedagogical Tools in Science Museums" was given by an expert in the area and several texts on the subject were discussed with students after they read them at home.

The didactic transposition of scientific knowledge and the communication process operating in science museums was illustrated during the visit to the exhibition Looking at the Sky, Measuring Earth ${ }^{5}$, that tells the story of Astronomy in the country, from the Portuguese navigators that used the sky and various instruments to guide themselves http://site mast.br/exposicoes hotsites/exposicao permanente olhar o ceu medir a terra/index. $\underline{\mathrm{html}}$ 
across the ocean arriving to what is nowadays Brazil, to the first scientific Brazilian expeditions to delimit and study their territory. The students could observe and manipulate some historic instruments to measure the altitude of stars and other angular distances, including compasses, cross-staffs, chip logs, astrolabes, quadrants, sextants, and also antique telescopes. This exhibition allowed discussing the social and historical implications of Astronomy and helped students to ascribe value to the national institutions that carry out important research in the area since the $1820 \mathrm{~s}$.

In addition, having undergone a process of appreciation of the scientific concepts, the participants stimulated curiosity about science in others, especially young girls and women visiting MAST, becoming themselves reference models.

\subsubsection{Social related activities}

Together with Astronomy topics, other subjects related to social matters were discussed with the students. Since one of the goals of the project is to prepare them for the future, gender issues that may play a role in their lives were brought to their attention. An extensive research called "Being a girl in Brazil" ${ }^{6}$ was presented to the students. The study is a collection of data and testimonies of thousands of girls from 6 to 14 years in an attempt to map their situation at home and at the school as well as the kind of daily activities they do (or do not), specially related to houseworking. The students felt identified by some aspects, for example, the lack of quality time to study or have fun at home, in comparison with their brothers, showing that girls are compelled to do domestic work while boys do not have that obligation. Another resource used to introduce the gender topic from the perspective of young girls was the documentary "Girl Rising"7, that brings to attention the hard situation of girls and teenagers around the word and the difficulties they have regarding access to education.

In one of the sessions, a debate with female researchers from the New Social and Political Cartography of the Amazon Program of the State of Maranhão University (UEMA) was organized. The aim was to present other fields, like History of Science and Anthropology, to the students where extensive investigations are also done, so they understand that research is not an activity exclusive of hard sciences. Moreover, they had the opportunity to learn from the vital experiences of the researchers, one of them being a member of a Quilombola ${ }^{8}$ community.

Another activity proposed to the students was the piece "Life of a Scientist" performed by the scientific theatre company "Telling Myths" during the Science and Technology National Week of 2016. The piece tells the story of a little girl who wants to be a scientist but her family does not allow it. To dissuade the girl from that "absurd idea" the mother takes her to an astronomy department so she can see with her own eyes how science is not a place for her. However, when they arrive, they meet the director of the department, who is a woman with a long and successful career. At the end, the mother changes her mind and goes out of the department thinking that her daughter will be an astronomer.

Finally, to keep a logbook of the project, a blog with the title "First Trip Scientists: Exploring the world"9 was created where students share their experiences. The use of this online resource was useful to exercise the writing and communication skills of the students. A (private) Facebook group was also created to foster a personal bond among students, and encourage them to seek, read and post news about Astronomy and science.

6 https://plan.org.br/por-ser-menina-no-brasil-crescendo-entre-direitos-e-violência 7 http://girlrising.com

${ }^{8}$ Quilombolas are the descendants of fugitive slaves who managed to escape and establish their own villages in the XIX century.

${ }^{9} \mathrm{https://cientistasdeprimeiraviagemblog}$.wordpress.com 


\section{The Participants}

The group of "Girls in the Museum" project consists of seven female high school students from the city of Rio de Janeiro, with ages between 15-18 years. This is a convenience sample, since the participants were the most easily accessible, and were either selected by a collaborating teacher or because the girls manifested interest to participate in the Project.

Four of the students attend the Julia Kubitschek State High School, located in the central area of Rio de Janeiro. All of them are part of the teacher formation program and have the aspiration of becoming teachers in future. Two participants study at the Technical College of the Federal Rural University of Rio de Janeiro, in the West part of the city. One of them knew about the project after participating in the Girls' Day 2016 event at MAST together with her mother. The other student had already been a summer intern at MAST during the summer of 2016. Only one student goes to a private school, the São Vicente de Paulo College, in the South of Rio de Janeiro, and learned about the project while visiting the Museum with her mother during the Sky Observation Program [10]. The latter three students had a manifest interest in science, and in particular in Astronomy, prior the beginning of the project.

\section{Goals and Methodology}

The main goal of this research was to evaluate the first phase of the project "Girls in the Museum" from the perspective of the participants. The study aimed to provide a diagnosis for the Project and propose new strategies for future editions. A specific goal was to verify possible changes in the students' viewpoints and perception towards science, in particular Astronomy, after the sessions of the first six-month training period.

The methodology used in the study was qualitative and based on the follow-up of the attitudes and opinions by the participants throughout the sessions. A participant observer position was adopted in order to document the relevant experiences lived during the meetings and survey the attitudes of the participants. Moreover, individual interviews were carried out, one before the beginning of the project and one after completing the first phase.

An initial individual semi-structured interview was conducted in the first meeting of the training period. Some questions were aimed at characterizing the demographic profile and the family situation of the interviewees while others sought to outline their initial interest in science. A second individual unstructured interview was conducted six months latter to register the opinion of the students regarding the adequacy of the content and the format of the project as well as their notions on the scientific topics covered. Special attention was given to the students' perception of science in order to compare with their thoughts before starting the project.

The method chosen to analyse the interviews is named the Discourse of the Collective Subject (DSC, Portuguese acronym) ${ }^{\mathbf{1 0}}$ [11]. This is a methodology widely used in Social Sciences to organize, categorize and tabulate qualitative data (in our case, speeches collected during interviews) through systematic and standardized criteria, in order to examine the discourse expressed by a collectivity (in our case, high school girls from the city of Rio de Janeiro).

In brief, the methodology works as follows: (1) the researcher collects the answers/speeches of a specific question from all participant girls; (2) the researcher identifies sentences in all answers/speeches collected, or key expressions (KE), that belong to the same central idea (CI) - the answer/speech of a single participant may contain more than one central idea, for example, when there is contradiction in the answer; (3) the researcher builds a discourse, or the so-called discourse of the collective subject (DSC), using all KE belonging to a single CI - this implies that the DSC

${ }^{10}$ As translated to English by the own authors. 
contains sentences expressed by various participants. To finalize, the researcher may introduce a few adjustments (for instance, by inserting connectors or missing words) so to bring the DSC to fruition. In addition, the DSC is written in first-person.

The advantage of this method is that it preserves the essence of the interviewee's speech, allowing the identification of thoughts, representations, beliefs, and values of a community or collective subject. The final discourses (presented in Section 5, in brackets) are synthesized by the combination of the speeches of all participants regarding a specific content category or central idea. They are expressed in the firstperson singular as if a collectivity were speaking through an individual.

Though the study presented here is clearly qualitative in nature (only 7 cases), the DSC allows us to measure how often each central idea appears through the intensity (frequency) operator. Further information about this methodology can be found in the contribution "What does the general public expect from a night-sky observation?" by Spinelli, et al.

\section{Results}

In this Section we present some of the main results derived from the evaluation analysis of the "Girls in the Museum" project. Some of the statements made here are illustrated with the discourses of the collective subject built using the responses of the students. Due to the limitation of space we cannot transcribe all the discourses here, we invite the readers to access the dissertation [12] for more details.

The purpose of the first interview was to learn about the interest and perception of science of the participants in the project. Questions were asked in this direction, for example: if they liked science subjects at school, which subject was their favourite or what they thought about science and the daily work of scientists. We wanted to know if the girls had any contact with Astronomy prior to the beginning of the project.

In this sense, four of them declared that they had visited a Planetarium together with schools or with their families at some point in their lives. Three of them had never visited a Planetarium or a Science Centre before coming to the MAST. Only two of the students had some initial factual knowledge about Astronomy. One of them did a few outreach courses at the University and the other was involved in a small scientific project about Mercury's transit at MAST during her school holidays. The student attending private school said she was very interested in science and had some previous contact due to her mother being a researcher in the area of Biophysics.

Regarding their scholar interests all students agreed they liked subjects like Mathematics, Chemistry, Physics and, especially, Biology. Four students pointed out that they liked science subjects but they found them difficult to understand. Only one of them said she considered herself good at STEM disciplines. Teachers' performance was referred to as a determining factor to stimulate interest in scientific topics by two of these students. All of them considered science as something important and mentioned positive aspects of it, as we see in the following discourse ${ }^{11}$ (intensity $=7$ ):

[Yes (I think science is important). Because science is essential. Everything we do involves science. The human being is always searching for more, always trying to discover new things, things that we cannot even imagine. Science is important because it gives you reasons to explain things. When we study science, we know exactly what is happening, and I think this is very good.]

\footnotetext{
11 We recall that the discourses of the collective subject, even though expressed in first person singular, are produced by combining the individual opinions of the participants about a specific topic, central idea, representing in this way the opinion of a collective.
} 
They recognized the job of a scientist is interesting, though some of them perceived it as an odd, distant world. Only the student whose mother is actually a scientist spoke differently. The resulting discourse was (intensity $=6$ ):

[(Being a scientist) I think it is a different world than ordinary people are used to, with a lot of technology. It must be a very interesting life because you study everything. Scientists look for things that have not yet been discovered, and that will be of great use to mankind.]

Moreover four participants had a stereotyped image of scientists (intensity $=4$ ):

[I imagine (a scientist) as a man, in a white coat, with glasses, in a laboratory, with a notebook writing things. Using a computer or test tubes. A figure like Einstein!]

In the final interview, conducted at the end of the training phase, the students expressed a high degree of satisfaction with the Project. The main reason for their approval was the knowledge and expertise they believe they acquired in various areas, which also stimulated their interest in science and research. They also pointed out that the Project greatly contributed to their lives, highlighting the positive aspects that participating in such an initiative could bring to their future. The discourse about this topic is transcribed here (intensity $=7$ ):

[I found the project very cool and interesting, I'm really enjoying it. I'm learning things I did not know, that I was always curious about, but I never really went after. It has stimulated my interest in the area and is motivating me to want to do research. It has positively added to my life. I think it will help me a lot and will bring chances for the future.]

During the interview, the students spoke freely about the adequacy of the Project's format and the covered topics that interested them most. We noticed that the participants liked more the Astronomy sessions, though they found interesting the social issues that were addressed too. The discourse of the collective subject was (intensity $=7$ ):

[I liked the talk about the Sun and the sunspots more. Also (I liked) the lecture about the galaxies and the speaker who came from the L'Oréal Foundation (Prof. Ana Chies Santos). She explained several things I did not know. I liked the way she communicated with us because she spoke in an inspiring way.]

Regarding the format of the sessions, the three students already interested in science liked theoretical talks more. On the contrary, students who are studying to become teachers enjoyed the practical workshops where they could "get their hands-on". The blog was mentioned as a useful tool to remember the concepts discussed along the session and to improve their writing abilities. The diversity of topics covered, the variety of activities (lectures, workshops, debates...) and the combination of the scientific and the educational dimensions were pointed out as positive aspects of the Project. This is shown in the discourses below corresponding to the "Format of the Project" central idea (intensity $=9$ ):

[I think it is very important to learn several aspects, like talks that are not related to Physics or Mathematics. We did not sit around calculating a lot of things (like in school). It's not only a science-focused project.]

[The project it is always very dynamic. There are lectures, then workshops, then we move to the blog and remember what we did. I loved writing about the lecture (about galaxies). When it is not didactic, it is scientific.]

Based on the analysed discourses, we verified that the format of the first period was adequate and fulfilled the expectations of the students. Moreover, they suggested other topics they would like to know more about, such as, dark matter, astrobiology, history of science or inclusion of non-traditional groups in science (for example, visually impaired people). These results are crucial to evaluate the program and formulate the next steps. 
The participants were questioned if they believed their vision of science had changed since the Project started and in which way. This was a key question to understand the real contribution of the Project regarding the students' perception of science. The students declared their view of science had changed due to their participation in the Project, in the sense of feeling it closer to their reality now. Based on the discourses, we observe that the Project minimized the fear and the apprehension about science they experienced before (intensity $=7$ ):

[The program wiped out the fear and doubt I had (about science) and now it seems that science is closer to us. Now we explain to our parents, to our friends. We see that it is not so difficult. If you study you can (do it).]

It is important to stress that the students seem to feel confident to discuss astronomy with the families and friends, meaning they are mediating even outside the museum. Two students said the project confirmed their thoughts about science and further encouraged them to choose a scientific career. Is worthy to notice, that one of participants is currently an undergraduate student in Astronomy at the Federal University of Rio de Janeiro (UFRJ). Based on personal testimonies expressed during the sessions (not in the interviews), we verify that she felt encouraged to choose Astronomy as degree because of the Project.

Based on the discourses, we can claim that the Project expanded the students' idea of a scientist, who is no longer regarded as a genius, but as a normal person with a job that everyone can do including, of course, women. In this context, they greatly valued being in contact with successful female scientists, highlighting the importance of making non-traditional role models accessible for young girls.

\section{Conclusion}

In this paper we presented the results of the evaluation of the first phase of "Girls in the Museum" from the point of view of the participants, in order to serve as a diagnose of the adequacy of the Project. The discourses of the collective subject show that the format of the training period, consisting of theoretical lectures and practical workshops and visits, was adequate and helped students to feel more confident about Astronomy.

The participants had a satisfactory opinion of the Project and were ready to learn more about science. This work was an exploratory study, since the second and third phases of the Project are happening still. We confirm that facilitating access to role models is fundamental to address the lack of women in science, making girls believe in their potential to choose scientific careers by seeing other women who have followed this path.

In future work, we will complete a more in-depth analysis, incorporating the material of the blog and new interviews that will be realized after the completion of the Project. We hope this research can serve as an example for similar initiatives for encouraging girls to like science in other science museums.

\section{References}

1. P. A. Bourdieu. Masculine Domination. RJ: Bertrand Brazil (1999).

2. G. A. Olinto. A inclusão das mulheres nas carreiras de ciência e tecnologia no Brasil. Inclusão Social, 5, 68 (2011).

3. C. Hill, C. Corbett \& A. St. Rose. Why so few? Women in science, technology, engineering and mathematics. American Association of University Women (2010).

4. E. C. C. Vasconcellos \& S. N. Brisolla. Presença feminina no estudo e no trabalho da ciência na Unicamp. Cadernos Pagu, 32, 215 (2009).

5. S. A. Viegas. A astronomia brasileira no feminino. História da Astronomia no Brasil, 2, 522 (2013). 
6. L. Bian, S. Leslie \& A. Cimpian. Gender stereotypes about intellectual ability emerge early and influence children's interests. Science, 355, 389 (2017).

7. C. Cesarsky \& H. Walker. Head count: statistics about women in astronomy. Astronomy \& Geophysics, 51, 33 (2010)

8. M. Marandino. Perspectivas da Pesquisa Educacional em Museus de Ciências. A Pesquisa em Ensino de Ciências no Brasil e suas Metodologias, 1, 89 (2006).

9. M. P. Bonatto, O. I. A Mendes \& M. I. Seibel. Ação mediada em museus de ciências: o caso do Museu da Vida. Casa de Oswaldo Cruz/Fiocruz, Museu da Vida, RJ (2007).

10. T. Bassallo. Dissertation "Ver o universo é uma coisa única" - o Programa de Observação do Céu segundo os visitantes do Museu de Astronomia e Ciências Afins"- Casa Oswaldo Cruz/Fiocruz, Museu da Vida (2016).

11. F. Lefèvre \& A. M. C. Lefèvre. Discurso do sujeito coletivo: um novo enfoque em pesquisas qualitativasCaxias do Sul: Educs (2003).

12. S. Benitez-Herrera. Dissertation "Inclusão pela divulgação da ciência: o caso do projeto Meninas no Museu de Astronomia e Ciências Afins"- Casa Oswaldo Cruz/Fiocruz, Museu da Vida (2017). 